\title{
Neuroprotective effects of allopurinol on spinal cord injury in rats: a biochemical and immunohistochemical study
}

\author{
M. Baloğlu¹, E. Gökalp Özkorkmaz² \\ ${ }^{1}$ Department of Physiotherapy, Diyarbakir Gazi Yasargil Education and Research Hospital, Diyarbakir, Turkey \\ 2Department of Histology and Embryology, Dicle University, School of Medicine, Diyarbakir, Turkey
}

[Received: 20 February 2019; Accepted: 13 March 2019]

Background: Lesion in spinal cord causes a cascade of events such as the apoptosis of neurons and eventually, neurological dysfunction. Neurologic damage developing after acute spinal cord injury is also related with necrosis and free radical formation. Allopurinol, a xanthine oxidase inhibitor, was shown to have protective effects in several studies. B-cell lymphoma 2 (BCl-2) family proteins regulate apoptosis. Apoptosis causes the death of neuronal cells, particularly neurons and oligodendrocytes in the spinal cord after lesion. Glial fibrillary acidic protein (GFAP) takes part in astrocyte and neuronal interconnection and synaptic transmission. Materials and methods: Male Sprague Dawley rats $(n=30)$ were divided as control, trauma, and trauma + allopurinol (i.p., $50 \mathrm{mg} / \mathrm{kg}$ of body weight) groups. Animals were applied a surgical procedure causing spinal cord injury and treated for 7 days then sacrificed under anaesthesia. The spinal cords were dissected, measurements of myeloperoxidase, malondialdehyde and glutathione were performed, remaining parts were fixed in 10\% formaldehyde solution for histological and immunohistochemical evaluations.

Results: Biochemical results exhibited an increase in myeloperoxidase levels in trauma group but a decrease in the allopurinol treatment group similar to malondialdehyde levels. Degenerative changes in multipolar and bipolar neurons together with apoptotic changes in some glial cells were observed in the trauma group whereas, mild degenerative changes were observed after allopurinol treatment. In the trauma group, negative GFAP expression in multipolar versus bipolar neuronal processes with a reduction in glial processes around blood vessels and positive GFAP expression were observed but, a regular and parallel positive GFAP expression of glial processes around blood vessels in the allopurinol treated group was apparent. Trauma group depicted a positive $\mathrm{BCl}-2$ expression in glial cells and in motor and bipolar neurons. On the contrary, negative BCl-2 expression was noticed in the trauma + allopurinol group.

Conclusions: This study is of importance to understand the effects of allopurinol in preventing degenerative changes in nerve and glial cells related to spinal cord injuries. (Folia Morphol 2019; 78, 4: 676-683)

Key words: allopurinol, glial fibrillary acidic protein, B-cell lymphoma 2, spinal cord injury, rat

Address for correspondence: Dr. E. Gökalp Özkorkmaz, Assistant Professor, PhD, Department of Histology and Embryology, Dicle University, School of Medicine, 21280, Diyarbakir, Turkey, tel: +90 412 2488001-16, ext: 4399 (faculty room), e-mail: egokalp62@hotmail.com 


\section{INTRODUCTION}

Motor, sensory and autonomic dysfunctions are consequences of spinal cord injury $(\mathrm{SCl})$ occurring on the cervical spine causing problems in cervical, thoracic, lumbar, and sacral levels under injury [3]. $\mathrm{SCl}$ are accompanied by apoptosis of neurons and the initiation of glial cells, which results in neurological dysfunction. Lesion on spinal cord triggers infiltration of inflammatory cells and irreversible loss of neurons $[15,35]$. Neurologic damage occurring after acute SCI involves necrosis after primary mechanic injury and secondary injury then, apoptosis takes place [5]. So, previous studies reveal strong evidence demonstrating the presence of apoptosis after $\mathrm{SCl}$.

Pathogenesis of spinal cord neuronal lesion after injury is also related with oxygen-derived free radical formation leading to oedema and inflammatory response. After spinal cord lesion disabilities and deficits such as; loss of motor, sensory and autonomic sensory system capabilities, muscle spasms, chronic pain, and urinary tract diseases may appear [1]. A study on imatinib was demonstrated that functional outcomes like locomotor capacity and bladder function and also histological parameters (tissue sparing, axonal sparing, astrogliosis, inflammation and BSCB permeability) were improved following spinal cord weight-drop lesion [2].

Allopurinol, [4-hydroxy-pyrazole(3,4-d) pyrimidine], a xanthine oxidase inhibitor, was shown to have protective effects during ischaemia [4] by blocking purine breakdown. It easily crosses the blood-brain barrier and throughout cerebral ischaemia takes part in the protection of cells [37]. Allopurinol is a free radical scavenger that is used to treat several diseases such as; vascular injury, inflammation [26], ischaemic heart disease [7, 38], heart failure [14], and myocardial protection during cardiac or aortic surgery or post-ischaemic reperfusion [39]. It is also used to treat gout [41], hyperuricaemia [28], and inflammatory arthritis with relatively minor adverse effects for a long time. Allopurinol prohibits the process of axonal damage and demyelination induced by oxidative stress and proinflammatory cytokines [27, 31]. Palmer et al. [27], reported that allopurinol administered $15 \mathrm{~min}$ after cerebral hypoxia-ischaemia in neonatal rats reduced brain oedema, neuronal necrosis, and cystic infarction. Allopurinol's neuroprotective mechanism was attributed to its ability to inhibit xanthine oxidase in previous studies that in the brain, xanthine oxidase is concentrated within endothelial cells, subject the blood-brain barier to free radical attack [40].
B-cell lymphoma 2 (Bcl-2) family proteins monitor apoptosis and regulate this complex molecular network. Various cellular events such as DNA damage, energy stress, loss of growth factor signalling and hypoxia can initiate apoptosis by activation of these proteins. The Bcl-2 family proteins take prominent roles such as regulation of mitochondrial or intrinsic apoptotic response [29]. Apoptosis causes the death of neuronal cells, particularly neurons and oligodendrocytes in the spinal cord after lesion, later corrupts axon myelin anatomical unit and gives rise to an interruption in impulse transmission leading to neuronal loss [30, 43].

Glial fibrillary acidic protein (GFAP) acts in astrocyte-neuronal interconnection and synaptic transmission [22]. As an intermediate filament protein GFAP is found in the skeleton of astroglia. Previous studies indicated that increased GFAP immunoreactivity is a sensible indicator of neuronal damage in tissue and an increase in GFAP is also an indicator of reactive astrocytosis. Damage caused by a trauma or disease in cerebral tissue or spinal cord cells is known to initiate acceleration in blood GFAP level [17, 36, 44].

In this experimental study, the role of allopurinol in rats with spinal cord injury and the immunohistochemical expression of GFAP and Bcl-2 proteins were investigated.

\section{MATERIALS AND METHODS}

\section{Animals}

Every single surgical methodology and the consequent care and healing of the animals utilised as a part of this investigation were in strict understanding with the National Institutes of Health (NIH Publications No. 8023, revised 1978) rules for animal care. All experimental protocols were approved by the Dicle University Animal Care and Use Committee. Male Sprague Dawley rats $(n=30)$ weighing 250-290 g were kept under the conditions of $22 \pm 1^{\circ} \mathrm{C}$ and $12 / 12 \mathrm{~h} \mathrm{light/dark}$ cycles with standard pellet and water ad libitum. All rats at the end of experiment were healthy and no difference in food/ /water consumption and body weight gain between experimental and control rats were observed. Rats were separated into three groups as; control group, trauma group and trauma + allopurinol group. Isotonic saline solution (an equal volume of allopurinol) was administered i.p. for 7 days in the control and trauma groups. Fifteen minutes following trauma, the allopurinol solution was injected intraperitoneally for 7 days at a concentration of $50 \mathrm{mg} / \mathrm{kg}$ of body weight (Urikoliz $300 \mathrm{mg}$, Ilsan, Turkey, $50 \mathrm{mg} / \mathrm{kg}$ ). Spinal cord tissue 
taken from L1-L2 spinal cord segments was extracted, fixed in a $10 \%$ formalin solution, and embedded in paraffin blocks for histopathologic examination in all groups. Sections ( $5 \mu \mathrm{m}$ thick) were obtained from paraffin blocks and stained with haematoxylin and eosin (H\&E) for light microscopy examination.

\section{Surgical procedure}

Experimental animals were anesthetised intraperitoneally with ketamine and chlorpromazine $75 \mathrm{mg} / \mathrm{kg}$ and $1 \mathrm{mg} / \mathrm{kg}$, separately [42]. Each rat was then positioned on a heating pad in a prone position and a rectal test was embedded. Under aseptic conditions, following T5-12 midline skin incision and paravertebral muscle dissection, spinous procedures and laminar arcs of T5-12 were evacuated. The particular relative angulation of the spinous procedures of the T9, T10, and T11 vertebrae was utilised as an imperative intraoperative landmark: T9 points caudally, T10 points directly dorsal, and T11 points rostrally. This delivers a solid "triangle" introduction that can be promptly checked whether the animal is positioned flat on the operating table. After the T11 and $\mathrm{T} 12$ vertebrae had been distinguished, a laminectomy was performed at T11 and T12 with Friedman-Pearson rongeurs. The clasp was then held open with a clasp utensil, with the lower cutting edge of the clasp passed extradurally completely around the spinal cord and nerve roots at the intersection between the $\mathrm{T} 11$ and $\mathrm{T} 12$ vertebrae, comparing to the L1-L2 spinal cord segmental level. The clasp was then quickly discharged from the tool to deliver a bilateral impact force and sustained dorsal-ventral compression. The compression of the spinal cord was kept up for $60 \mathrm{~s}$ before expulsion of the clasp. The muscles were then sutured utilising 3- 0 polyglactin sutures, and the skin was shut with Michel clips [24]. Following surgical system, the rats were put in warming chamber and their body temperatures were kept up at roughly $37^{\circ} \mathrm{C}$ until the point when they were totally conscious. An hour after the spinal cord injury, only saline was injected intraperitoneally to the trauma group.

\section{Histological preparation and analysis}

At the end of the experiment, all animals were anesthetised via the intraperitoneal administration of ketamine $\mathrm{HCl}(0.15 \mathrm{~mL} / 100 \mathrm{~g}$ body weight). The spinal cords were dissected. The sections were subjected to H\&E staining for observation under a light microscope.

\section{Haematoxylin and eosin staining procedure}

1. Deparaffinised sections, two changes of xylene, 10 min each.

2. Re-hydrate in two changes of absolute alcohol, 5 min each.

3. $95 \%$ alcohol for $2 \mathrm{~min}$ and $70 \%$ alcohol for $2 \mathrm{~min}$.

4. Wash briefly in distilled water.

5. Stain in Harris haematoxylin solution for $8 \mathrm{~min}$.

6. Wash in running tap water for $5 \mathrm{~min}$.

7. Differentiate in $1 \%$ acid alcohol for $30 \mathrm{~s}$.

8. Wash running tap water for $1 \mathrm{~min}$.

9. Bluing in $0.2 \%$ ammonia water or saturated lithium carbonate solution for $30 \mathrm{~s}$ to $1 \mathrm{~min}$.

10. Wash in running tap water for $5 \mathrm{~min}$.

11. Rinse in $95 \%$ alcohol, 10 dips.

12. Counterstain in eosin-phloxine solution for $30 \mathrm{~s}$ to $1 \mathrm{~min}$.

13. Dehydrate through $95 \%$ alcohol, two changes of absolute alcohol, $5 \mathrm{~min}$ each.

14. Clear in two changes of xylene, 5 min each.

15. Mount with xylene based mounting medium.

\section{Immunohistochemical staining}

An antigen-retrieval process was performed in citrate buffer solution (pH 6.0) two times: first for $8 \mathrm{~min}$ and afterward for $5 \mathrm{~min}$ in a microwave oven at $700 \mathrm{~W}$. They were permitted to cool to room temperature for $20 \mathrm{~min}$ and washed in distilled water twice for $6 \mathrm{~min}$. Endogenous peroxidase action was hindered in $0.1 \%$ hydrogen peroxide for $15 \mathrm{~min}$. An ultra $\mathrm{V}$ block (Histostain-Plus Kit, Invitrogen, Carlsbad, CA) was connected for $10 \mathrm{~min}$ before the use of the primary antibodies (Bcl-2 antibody, mouse monoclonal, 1/100, Santa Cruz Biotechnology, US) and GFAP antibody (mouse monoclonal, 1/100, Abcam, UK) overnight. The secondary antibody (Histostain-Plus Kit, Invitrogen, Carlsbad, CA) was connected for $15 \mathrm{~min}$. At that point, the slides were exposed to streptavidin-peroxidase for $15 \mathrm{~min}$. Diaminobenzidine (DAB, Invitrogen, Carlsbad, CA) was utilised as a chromogen. Control slides were set up as specified above yet overlooking the primary antibodies. In the wake of counterstaining with haematoxylin, washing in tap water for $5 \mathrm{~min}$, and in refined water for $2 \times 5 \mathrm{~min}$, the slides were mounted.

\section{Measurement of myeloperoxidase activity}

The myeloperoxidase (MPO) activity levels were measured using the method described by Hillegass et al. [18]. Spinal cord tissue specimens were homog- 
Table 1. Biochemical results of experimental groups

\begin{tabular}{lccc}
\hline & Control & Trauma & Trauma + allopurinol \\
\hline Malondialdehyde $[\mathrm{nmol} / \mathrm{g}]$ & $27.75 \pm 0.85$ & $41.95 \pm 0.72^{* *}$ & $28.32 \pm 0.82++$ \\
Glutathione $[\mu \mathrm{mol} / \mathrm{g}]$ & $1.46 \pm 0.04$ & $0.72 \pm 0.05^{*}$ & $1.32 \pm 0.04++$ \\
Myeloperoxidase $[\mathrm{U} / \mathrm{g}]$ & $3.37 \pm 0.05$ & $7.54 \pm 0.58^{* *}$ & $6.75 \pm 0.49+$ \\
\hline
\end{tabular}

Values are represented as mean \pm standard deviation. Each group consists of ten rats.

${ }^{*} p<0.05$, vs. control; ${ }^{* *} p<0.001$, vs. control; $+p<0.01$, trauma + allopurinol vs. trauma; $++p<0.001$, trauma + allopurinol vs. trauma

enised in $50 \mathrm{mM}$ potassium phosphate buffer with a pH of 6.0 and centrifuged at $41,400 \mathrm{~g}$ for $10 \mathrm{~min}$. The pellets were then suspended in $50 \mathrm{mM}$ PB containing $0.5 \%$ hexadecyl trimethyl-ammonium bromide (HETAB). After three freezes and defrost cycles, with sonication between cycles, the samples were centrifuged at $41,400 \mathrm{~g}$ for $10 \mathrm{~min}$. Aliquots $(0.3 \mathrm{~mL})$ were added to $2.3 \mathrm{~mL}$ of the response mixture containing $50 \mathrm{mM} \mathrm{PB}$, o-dianisidine, and $20 \mathrm{mM} \mathrm{H}_{2} \mathrm{O}_{2}$ solution. One unit of enzyme action was characterised as the measure of MPO presence that caused an adjustment in absorbance, estimated at $460 \mathrm{~nm}$ for $3 \mathrm{~min}$. MPO action was expressed as $\mathrm{U} / \mathrm{g}$ tissue.

\section{Malondialdehyde and glutathione assays}

Spinal cord tissue samples were homogenized with super cold $150 \mathrm{mM} \mathrm{KCl}$ for the assurance of malondialdehyde (MDA) and glutathione (GSH) levels. The MDA levels were tested for the products of lipid peroxidation and the outcomes are expressed as nmol MDA/g tissue [21]. GSH was resolved by a spectrophotometric technique in light of the utilisation of Ellman's reagent and the outcomes are expressed as $\mu \mathrm{mol} \mathrm{GSH} / \mathrm{g}$ tissue [11].

\section{Statistical analysis}

All information is expressed as means \pm standard deviation. Groups of information were contrasted and an analysis of variance (ANOVA) trailed by Tukey's various correlation samples. Estimations of $p$ value ( $p<0.05$, vs. control; $p<0.001$, vs. control; $p<0.01$, trauma + allopurinol vs. trauma; $p<0.001$, trauma + + allopurinol vs. trauma) were considered as significant.

\section{RESULTS}

Control, trauma and trauma + allopurinol groups were analysed for biochemical data. MPO action, which is acknowledged as an indicator of inflammatory cells, was fundamentally higher in the spinal cord

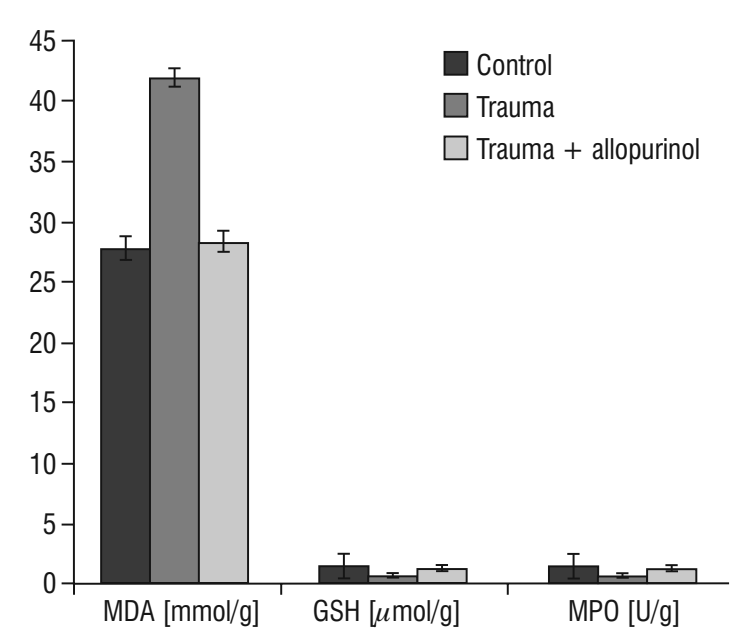

Figure 1. Biochemical results relevant to the study groups; GSH glutathione; MDA — malondialdehyde; MPO — myeloperoxidase.

tissues of disturbed rats than those of the control group $(p<0.001)$.

Allopurinol treatment reduced spinal cord tissue MPO levels $(p<0.01)$ when compared to the trauma group. The injury caused a significant increment in the MDA levels $(p<0.001)$ with a reduction in GSH levels $(p<0.001)$. Allopurinol caused a decrease in MDA levels and re-established the GSH content at day 7 (Table 1, Fig. 1).

\section{Histopathologic findings}

In the cross-section of the control group; spinal cord, ependymal canal, which was paved with cylindrical epithelium, multipolar and bipolar neurons were diffusely distributed in substantia grisea. In the substantia alba layer, regular and nerve extension of the glial cells were observed (Fig. 2a). In the trauma group, hyperplasia of epithelial cells with dilatation of the ependymal canal, and degenerative changes in multipolar and bipolar neurons together with apoptotic changes in some glial cells were observed. In the substantia grisea and alba layer, 
congestion in the vessels and degeneration in the endothelial cells and ruptures in the nerve extensions were observed (Fig. 2b). In the group treated with allopurinol after trauma, mild degenerative changes were observed in multipolar and bipolar neurons compared to the trauma group, while the structure of the blood vessels in the endothelial cells was preserved (Fig. 2c).

\section{Immunohistochemical findings}

In the control group, Bcl-2 was weakly expressed in the cytoplasm of neurons of anterior and dorsal horn and intermediate zone. Occasionally, positive glial cells were observed in substantia grisea layer (Fig. 3a). Bcl-2 expression was positive in glial cells and degenerative changes were seen in motor neuron and bipolar neurons in the trauma group. $\mathrm{Bcl}-2 \mathrm{ex}-$ pression was positive in glial cells in some multipolar and bipolar neurons after trauma (Fig. 3b). Negative Bcl-2 expression was observed in multipolar, bipolar and glial cells in the group treated with allopurinol after trauma (Fig. 3c). GFAP expression was positive in the control group sections and in the extension of multipolar bipolar neurons and glial processes (Fig. 4a). In the trauma group, GFAP expressions were evaluated as positive in degenerative structures in neurons and glial processes with irregular distribution of nerve extensions around degenerative structures in dilated blood vessels. In the trauma group, a decrease in astrocyte processes and a GFAP positive reaction were observed in the substantia grisea region (Fig. 4b). In post-traumatic allopurinol group, it was observed that the extension of the glial cells was in parallel with the extension of the neurons around the blood vessels in the multipolar and bipolar neurons and GFAP protein expression was observed (Fig. 4c).

\section{DISCUSSION}

Spinal cord injuries may be caused by damage to the vertebrae, ligaments or spinal discs or the spinal cord itself. It has been reported that $\mathrm{SCl}$ may delay the repair of large thoracoabdominal aortic diseases for ischaemic reasons. It was also reported that intercostal and lumbar artery blood flow in the spinal cord and postoperative neurological deficiencies occurred in many cases [19, 32].

A significant output of $\mathrm{SCl}$ is the formation of oxidative stress. Oxidative stress plays a critical role in the pathophysiology of $\mathrm{SCl}$ is long known fact [10, $12,33]$. After lesion, apoptosis gives rise to the death of cells such as; neuronal cells, oligodendrocytes and also neurons in the spinal cord, and even more breaks down the axon myelin anatomical unit and prohibits impulse conduction, leading to neuronal loss [30, 43]. After spinal cord lesion, inflammation of the spinal cord and obstructed vascular structure besides apoptotic changes in neurons can be seen. When apoptosis of neurons and glial cells is retained after the lesion, loss in the nerve tissue can be reduced and spinal cord lesion may become improved. Inflammatory reactions are significant components of the secondary lesion and they are supposed to be a part in controlling the pathogenesis of chronic $\mathrm{SCl}$ and possess a prominent role in nerve lesion and also act in regenerative reactions [16]. Inflammatory reactions may attend apoptosis of neurons and oligodendrocytes in scar formation also causing a reduction of neuronal capacity [34]. In the trauma group of our study, hyperplasia of epithelial cells with dilatation of the ependymal canal, and degenerative changes in multipolar and bipolar neurons together with apoptotic changes in some glial cells and congestion in the blood vessels and degeneration in the endothelial cells and ruptures in the nerve extensions were observed (Fig. 2b). In the group treated with post-traumatic allopurinol, mild degenerative changes were observed in the multipolar and bipolar neurons compared to the trauma group (Fig. 2c).

A study of Chen et al. [9] presented that in transgenic mice, over-expression of $\mathrm{Bcl}-2$ by gene transfer caused to a decline in infarction after permanent and transient central ischaemia. Expression of $\mathrm{Bcl}-2$ gene, acting as the apoptosis inhibitor, seems to protect cells from apoptosis, especially motor neurons of the spinal cord [9]. In our study, an increase in Bcl-2 expression was observed in glial cells in multipolar and bipolar neurons after apoptotic changes in glial cells in some of the endothelial cells (Fig. 3a). Negative Bcl-2 expression was observed in glial cells and multipolar and bipolar neurons in the post-traumatic allopurinol treated group (Fig. 3b).

Baloglu et al. [6] found a decrease in the apoptosis of nerve cells and glial cells by the application of Potentilla fulgens after SCl. They suggested that Potentilla fulgens reduced the amount of so-called inflammatory cells and stimulated angiogenetic progression by affecting the cytokine mechanism.

Glial fibrillary acidic protein is a brain-specific protein that acts as the major integral component of the cell skeleton of astrocytes. After brain injury, 

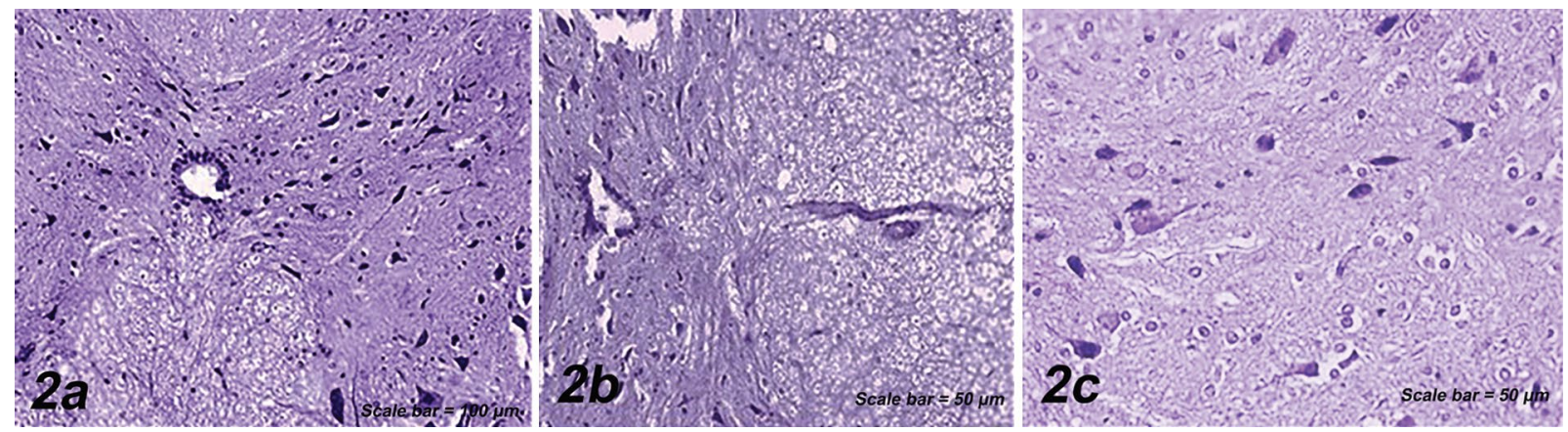

Figure 2. a. Haematoxylin and eosin (H\&E) staining (control group). Diffuse distribution of multipolar and bipolar neurons in substantia grisea, regular nerve extensions of the glial cells in substantia grisea and alba. Scale bar $=100 \mu \mathrm{m} ; \mathbf{b}$. H\&E staining (trauma group). Hyperplasia in ependymal cells, dilatation in ependymal channel, degenerative changes in multipolar and bipolar neurons, apoptotic changes in some glial cells, congestion in the blood vessels of the substantia grisea and alba layer. Scale bar $=50 \mu \mathrm{m} ; \mathbf{c}$. H\&E staining (trauma + allopurinol group). Moderate degenerative changes in multipolar and bipolar neurons. Scale bar $=50 \mu \mathrm{m}$.
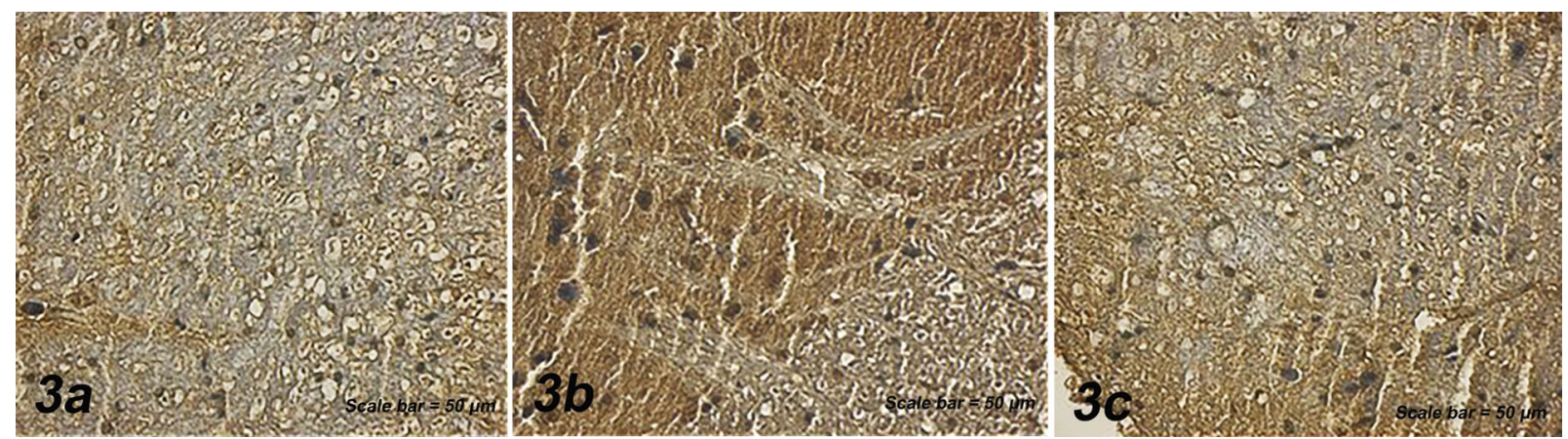

Figure 3. a. B-cell lymphoma 2 (Bcl-2) immunostaining (control group). Weak $\mathrm{Bcl} 2$ expression in the cytoplasm of neurons of anterior horn, dorsal horn and intermediate zone. Scale bar $=50 \mu \mathrm{m} ; \mathbf{b}$. Bcl-2 immunostaining (trauma group). Positive Bcl-2 expression in glial cells and in motor neuron, bipolar neurons. Scale bar $=50 \mu \mathrm{m}$; c. Bcl-2 immunostaining (trauma + allopurinol group). Negative Bcl-2 expression in multipolar, bipolar and glial cells in allopurinol group. Scale bar $=50 \mu \mathrm{m}$.
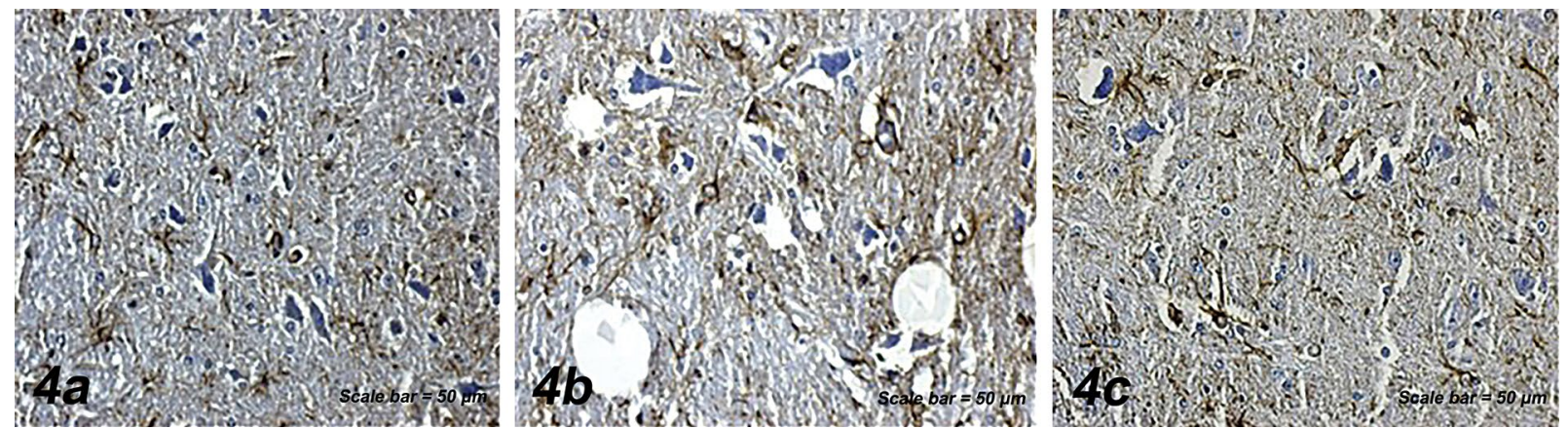

Figure 4. a. Glial fibrillary acidic protein (GFAP) immunostaining (control group). Positive GFAP expression in multipolar bipolar neurons and glial processes. Scale bar $=50 \mu \mathrm{m} ; \mathbf{b}$. GFAP immunostaining (trauma group). Negative GFAP expression in multipolar versus bipolar neuron processes while reduction in glial processes around blood vessels and positive GFAP expression. Scale bar $=50 \mu$ m; c. GFAP immunostaining (trauma + allopurinol group). Regular and parallel positive GFAP expression of glial processes around blood vessels. Scale bar $=50 \mu \mathrm{m}$.

GFAP releases the brain cells into the interstitial fluid in the environment and causes deterioration in the blood-brain barrier [23]. In many pathological con- ditions of the central nervous system and astrocytes, GFAP expression is increased. Studies on experimental animals revealed GFAP positive expression in astro- 
glial cells following traumatic brain injury $[17,44]$. Allopurinol is a specific inhibitor of xanthine oxidase, and it blocks the synthesis of xanthine from hypoxanthine and inhibits the formation of free radical superoxide [13]. In the trauma group of our study, GFAP expression in glial cells was evaluated as positive with degenerative neuron and a decrease in astrocytic ankles around dilated blood vessels (Fig. 4b). In the allopurinol treated group, glial feet around the blood vessel were regular and it was showed that GFAP protein expression increased in multipolar and bipolar neuron extensions (Fig. 4c).

Studies have shown that allopurinol leads to a decrease in the levels of free radical production and reduces tissue damage associated with $\mathrm{I} / \mathrm{R}$ injury $[8,13]$. It is both a strong xanthine oxidase inhibitor and an agent that decreases ischaemia related mitochondrial dysfunction $[8,20]$. As a result of a study by Moorhouse et al. [25], high doses have been suggested for the neuroprotective effects of allopurinol. It has also been shown that high levels of allopurinol and its metabolite oxypurinol in the blood can act as a scavenger and move hydroxyl radical and transition metal chelating agents [10]. On the contrary, another study indicated that the high dose allopurinol had an intraperitoneal protective effect but showed no therapeutic effect in transient focal cerebral ischaemia in the three-vessel occlusion model in rats [20].

Despite the results, there are a few limitations. Allopurinol may be applied for a longer period of time; however, we applied for 7 days and examined its short-term effect. We also preferred a lower dose, unlike high doses, not to enable a toxic effect. Known side effects of allopurinol are dermatologic (pruritic, erythematous, or macropapular eruptions), hematologic (leukopenia and/or eosinophilia, white blood count abnormalities), and hepatologic (increase in liver enzymes) [25] so, it was investigated whether allopurinol has an osteoblastic effect at lower dosages, since short-term administration at minimal concentrations would be more appropriate.

\section{CONCLUSIONS}

We think that GFAP expression in glial processes deteriorated in the multipolar, bipolar neuron extensions and blood vessel environment after $\mathrm{SCl}$ and in inflammatory response after trauma and tissue damage. We are in the opinion that allopurinol has an antioxidative effect and it may induce GFAP protein activity in traumatic SCl which may affect the repair process in nerve connections and ependymal cells after the trauma. As a conclusion, allopurinol can partially prevent degenerative changes in nerve cells and glial cells and decrease apoptotic changes due to $\mathrm{BCl}-2$ expression.

\section{REFERENCES}

1. Abrams GM, Ganguly K. Management of chronic spinal cord dysfunction. Continuum (Minneap Minn). 2015; 21 (1 Spinal Cord Disorders): 188-200, doi: 10.1212/01.CON.0000461092.86865.a4, indexed in Pubmed: 25651225.

2. Abrams MB, Nilsson I, Lewandowski SA, et al. Imatinib enhances functional outcome after spinal cord injury. PLoS One. 2012; 7(6): e38760, doi: 10.1371/journal. pone.0038760, indexed in Pubmed: 22723886.

3. Ahuja CS, Wilson JR, Nori S, et al. Traumatic spinal cord injury. Nat Rev Dis Primers. 2017; 3: 17018, doi: 10.1038/ nrdp.2017.18, indexed in Pubmed: 28447605.

4. Akdemir $\mathrm{H}$, Aşik Z, Paşaoğlu $\mathrm{H}$, et al. The effect of allopurinol on focal cerebral ischaemia: an experimental study in rabbits. Neurosurg Rev. 2001; 24(2-3): 131-135, indexed in Pubmed: 11485235.

5. Anderson DK, Means ED, Waters TR, et al. Microvascular perfusion and metabolism in injured spinal cord after methylprednisolone treatment. J Neurosurg. 1982; 56(1): 106-113, doi: 10.3171/jns.1982.56.1.0106, indexed in Pubmed: 7054403.

6. Baloğlu M, Çetin A, Tuncer MC. Neuroprotective effects of Potentilla fulgens on spinal cord injury in rats: an immunohistochemical analysis. Folia Morphol. 2018; 78(1): 1-7, doi: 10.5603/FM.a2018.0050, indexed in Pubmed: 30402877.

7. Berry CE, Hare JM. Xanthine oxidoreductase and cardiovascular disease: molecular mechanisms and pathophysiological implications. J Physiol. 2004; 555(Pt 3): 589-606, doi: 10.1113/jphysiol.2003.055913, indexed in Pubmed: 14694147.

8. Canbaz S, Duran E, Ege T, et al. The effects of intracoronary administration of vitamin $E$ on myocardial ischemia-reperfusion injury during coronary artery surgery. Thorac Cardiovasc Surg. 2003; 51(2): 57-61, doi: 10.1055/s-200338983, indexed in Pubmed: 12730811.

9. Chen MH, Ren QX, Yang WF, et al. Influences of HIF-l $\alpha$ on $\mathrm{Bax} / \mathrm{Bcl}-2$ and VEGF expressions in rats with spinal cord injury. Int J Clin Exp Pathol. 2013; 6(11): 2312-2322, indexed in Pubmed: 24228092.

10. Christie SD, Comeau B, Myers T, et al. Duration of lipid peroxidation after acute spinal cord injury in rats and the effect of methylprednisolone. Neurosurg Focus. 2008; 25(5): E5, doi: 10.3171/FOC.2008.25.11.E5, indexed in Pubmed: 18980479.

11. del Rayo Garrido M, Silva-García R, García E, et al. Therapeutic window for combination therapy of A91 peptide and glutathione allows delayed treatment after spinal cord injury. Basic Clin Pharmacol Toxicol. 2013; 112(5): 314-318, doi: 10.1111/bcpt.12023, indexed in Pubmed: 23057752.

12. DeRuisseau LR, Recca DM, Mogle JA, et al. Metallothionein deficiency leads to soleus muscle contractile dysfunction following acute spinal cord injury in mice. Am J Physiol Regul Integr Comp Physiol. 2009; 297(6): R1795-R1802, doi: 10.1152/ajpregu.00263.2009, indexed in Pubmed: 19828842

13. Erkut B, Özyazıcıoğlu A, Karapolat BS, et al. Effects of ascorbic Acid, alpha-tocopherol and allopurinol on ischemia-reperfusion injury in rabbit skeletal muscle: an ex- 
perimental study. Drug Target Insights. 2007; 2: 249-258, indexed in Pubmed: 21901079.

14. Farquharson CAJ, Butler R, Hill A, et al. Allopurinol improves endothelial dysfunction in chronic heart failure. Circulation. 2002; 106(2): 221-226, doi: 10.1161/01. cir.0000022140.61460.1d, indexed in Pubmed: 12105162.

15. Fouad K, Tetzlaff W. Rehabilitative training and plasticity following spinal cord injury. Exp Neurol. 2012; 235(1): 91-99, doi: 10.1016/j.expneurol.2011.02.009.

16. Genovese T, Esposito E, Mazzon E, et al. Absence of endogenous interleukin-10 enhances secondary inflammatory process after spinal cord compression injury in mice. J Neurochem. 2009; 108(6): 1360-1372, doi: 10.1111/j.14714159.2009.05899.x, indexed in Pubmed: 19183262.

17. Hausmann R, Riess R, Fieguth $A$, et al. Immunohistochemical investigations on the course of astroglial GFAP expression following human brain injury. Int J Legal Med. 2000; 113(2): 70-75, indexed in Pubmed: 10741479.

18. Hillegass LM, Griswold DE, Brickson B, et al. Assessment of myeloperoxidase activity in whole rat kidney. J Pharmacol Methods. 1990; 24(4): 285-295, indexed in Pubmed: 1963456.

19. Hirose K, Okajima K, Taoka Y, et al. Activated protein C reduces the ischemia/reperfusion-induced spinal cord injury in rats by inhibiting neutrophil activation. Ann Surg. 2000; 232(2): 272-280, doi: 10.1097/00000658-20000800000018, indexed in Pubmed: 10903607.

20. Işik N, Berkman MZ, Pamir MN, et al. Effect of allopurinol in focal cerebral ischemia in rats: an experimental study. Surg Neurol. 2005; 64 Suppl 2: S5-10, doi: 10.1016/j. surneu.2005.07.040, indexed in Pubmed: 16256842.

21. Jia YF, Gao HL, Ma L, et al. Effect of nimodipine on rat spinal cord injury. Genet Mol Res. 2015; 14(1): 1269-1276, doi: 10.4238/2015.February.13.5, indexed in Pubmed: 25730065.

22. McCall MA, Gregg RG, Behringer RR, et al. Targeted deletion in astrocyte intermediate filament (Gfap) alters neuronal physiology. Proc Natl Acad Sci U S A. 1996; 93(13): 6361-6366, doi: 10.1073/pnas.93.13.6361, indexed in Pubmed: 8692820.

23. Missler U, Wiesmann M, Wittmann G, et al. Measurement of glial fibrillary acidic protein in human blood: analytical method and preliminary clinical results. Clin Chem. 1999; 45(1): 138-141, indexed in Pubmed: 9895354.

24. Moonen G, Satkunendrarajah K, Wilcox JT, et al. A New Acute Impact-Compression Lumbar Spinal Cord Injury Model in the Rodent. J Neurotrauma. 2016; 33(3): 278-289, doi: 10.1089/ neu.2015.3937, indexed in Pubmed: 26414192.

25. Moorhouse PC, Grootveld M, Halliwell B, et al. Allopurinol and oxypurinol are hydroxyl radical scavengers. FEBS Lett. 1987; 213(1): 23-28, doi: 10.1016/0014-5793(87)81458-8, indexed in Pubmed: 3030809.

26. Pacher P, Nivorozhkin A, Szabó C. Therapeutic effects of xanthine oxidase inhibitors: renaissance half a century after the discovery of allopurinol. Pharmacol Rev. 2006; 58(1): 87-114, doi: 10.1124/pr.58.1.6, indexed in Pubmed: 16507884 .

27. Palmer C, Towfighi J, Roberts RL, et al. Allopurinol administered after inducing hypoxia-ischemia reduces brain injury in 7-day-old rats. Pediatr Res. 1993; 33(4 Pt 1): 405-411, doi: 10.1203/00006450-199304000-00018, indexed in Pubmed: 8479823.

28. Pea F. Pharmacology of drugs for hyperuricemia. Mechanisms, kinetics and interactions. Contrib Nephrol. 2005; 147: 35-46, doi: 10.1159/000082540, indexed in Pubmed: 15604604.
29. Reed JC. BCl-2 and the regulation of programmed cell death. J Cell Biol. 1994; 124(1-2): 1-6, doi: 10.1083/ jcb.124.1.1, indexed in Pubmed: 8294493.

30. Ren Yi, Young W. Managing inflammation after spinal cord injury through manipulation of macrophage function. Neural Plast. 2013; 2013: 945034, doi: 10.1155/2013/945034, indexed in Pubmed: 24288627.

31. Rodríguez-Fanjul J, Durán Fernández-Feijóo C, LopezAbad $M$, et al. Neuroprotection with hypothermia and allopurinol in an animal model of hypoxic-ischemic injury: Is it a gender question? PLoS One. 2017; 12(9): e0184643, doi: 10.1371/journal.pone.0184643, indexed in Pubmed: 28931035.

32. Roseborough G, Gao D, Chen L, et al. The mitochondrial K-ATP channel opener, diazoxide, prevents ischemia-reperfusion injury in the rabbit spinal cord. Am J Pathol. 2006; 168(5): 1443-1451, doi: 10.2353/ajpath.2006.050569, indexed in Pubmed: 16651612.

33. Savas $M$, Verit $A$, Ciftci $H$, et al. Oxidative stress in $B P H$. JNMA J Nepal Med Assoc. 2009; 48(173): 41-45, indexed in Pubmed: 19529057.

34. Shen LF, Cheng H, Tsai MC, et al. PAL31 may play an important role as inflammatory modulator in the repair process of the spinal cord injury rat. J Neurochem. 2009; 108(5): 1187-1197, doi: 10.1111/j.1471-4159.2008.05865.x, indexed in Pubmed: 19141070.

35. Silva NA, Sousa N, Reis RL, et al. From basics to clinical: a comprehensive review on spinal cord injury. Prog Neurobiol. 2014; 114: 25-57, doi: 10.1016/j.pneurobio.2013.11.002, indexed in Pubmed: 24269804.

36. Sofroniew MV, Vinters HV. Astrocytes: biology and pathology. Acta Neuropathol. 2010; 119(1): 7-35, doi: 10.1007/ s00401-009-0619-8, indexed in Pubmed: 20012068.

37. Soloniuk DS, Perkins E, Wilson JR. Use of allopurinol and deferoxamine in cellular protection during ischemia. Surg Neurol. 1992; 38(2): 110-113, doi: 10.1016/00903019(92)90087-4, indexed in Pubmed: 1509342.

38. Stone PH. Allopurinol a new anti-ischemic role for an old drug. J Am Coll Cardiol. 2011; 58(8): 829-830, doi: 10.1016/j.jacc.2011.02.072, indexed in Pubmed: 21835318.

39. Talwar S, Sandeep JA, Choudhary SK, et al. Effect of preoperative administration of allopurinol in patients undergoing surgery for valvular heart diseases. Eur J Cardiothorac Surg. 2010; 38(1): 86-90, doi: 10.1016/j. ejcts.2010.01.027, indexed in Pubmed: 20188583.

40. Terada LS, Willingham IR, Rosandich ME, et al. Generation of superoxide anion by brain endothelial cell xanthine oxidase. J Cell Physiol. 1991; 148(2): 191-196, doi: 10.1002/ jcp.1041480202, indexed in Pubmed: 1652587.

41. Terkeltaub R. Gout. Novel therapies for treatment of gout and hyperuricemia. Arthritis Res Ther. 2009; 11(4): 236, doi: 10.1186/ar2738, indexed in Pubmed: 19664185.

42. Toklu HZ, Hakan T, Celik H, et al. Neuroprotective effects of alpha-lipoic acid in experimental spinal cord injury in rats. J Spinal Cord Med. 2010; 33(4): 401-409, doi: 10.1080/10 790268.2010.11689719, indexed in Pubmed: 21061900.

43. Wu Y, Yang L, Mei X, et al. Selective inhibition of STAT1 reduces spinal cord injury in mice. Neurosci Lett. 2014; 580: 7-11, doi: 10.1016/j.neulet.2013.11.055, indexed in Pubmed: 24321405.

44. Yu HM, Yuan TM, Gu WZ, et al. Expression of glial fibrillary acidic protein in developing rat brain after intrauterine infection. Neuropathology. 2004; 24(2): 136-143, doi: 10.1111/j.1440-1789.2003.00539.x. 